Article

\title{
Comparison of LiDAR and Digital Aerial Photogrammetry for Characterizing Canopy Openings in the Boreal Forest of Northern Alberta
}

\author{
Annette Dietmaier ${ }^{1, *(1)}$, Gregory J. McDermid ${ }^{2}{ }^{\circledR}$, Mir Mustafizur Rahman ${ }^{2}{ }^{(}$, Julia Linke ${ }^{2}$ and \\ Ralf Ludwig ${ }^{3}$ \\ 1 Institute of Geography, University of Augsburg, Universitätsstr. 1a, D-86159 Augsburg, Germany \\ 2 Department of Geography, University of Calgary, Calgary, AB T2N 1N4, Canada \\ 3 Department of Geography, Ludwig-Maximilians-Universität, Luisenstr. 37, D-80333 Munich, Germany \\ * Correspondence: annette.dietmaier@geo.uni-augsburg.de
}

Received: 28 June 2019; Accepted: 13 August 2019; Published: 16 August 2019

check for updates

\begin{abstract}
Forest canopy openings are a key element of forest structure, influencing a host of ecological dynamics. Light detection and ranging (LiDAR) is the de-facto standard for measuring three-dimensional forest structure, but digital aerial photogrammetry (DAP) has emerged as a viable and economical alternative. We compared the performance of LiDAR and DAP data for characterizing canopy openings and no-openings across a 1- $\mathrm{km}^{2}$ expanse of boreal forest in northern Alberta, Canada. Structural openings in canopy cover were delineated using three canopy height model (CHM) alternatives, from (i) LiDAR, (ii) DAP, and (iii) a LiDAR/DAP hybrid. From a point-based detectability perspective, the LiDAR CHM produced the best results ( $87 \%$ overall accuracy), followed by the hybrid and DAP models ( $47 \%$ and $46 \%$, respectively). The hybrid and DAP CHMs experienced large errors of omission (9-53\%), particularly with small openings up to $20 \mathrm{~m}^{2}$, which are an important element of boreal forest structure. By missing these, DAP and hybrid datasets substantially under-reported the total area of openings across our site $\left(152,470 \mathrm{~m}^{2}\right.$ and $159,848 \mathrm{~m}^{2}$, respectively) compared to LiDAR $\left(245,920 \mathrm{~m}^{2}\right)$. Our results illustrate DAP's sensitivity to occlusions, mismatched tie points, and other optical challenges inherent to using structure-from-motion workflows in complex forest scenes. These under-documented constraints currently limit the technology's capacity to fully characterize canopy structure. For now, we recommend that operational use of DAP in forests be limited to mapping large canopy openings, and area-based attributes that are well-documented in the literature.
\end{abstract}

Keywords: LiDAR; photogrammetry; forest structure; forest openings; canopy openings; canopy gaps

\section{Introduction}

Canopy openings occur regularly and at various spatial scales throughout a forest, due to numerous exogenous and endogenous factors. In the boreal forest of Alberta, Canada, large openings are caused by fires [1], insect manifestation [2], windthrow [3], anthropogenic disturbances [4,5], and persistent suboptimal growing conditions associated with excessive soil moisture [6], water, or rock outcroppings [7]. Smaller openings might be the outcome of individual limb fall or the death of single trees [8]. In all cases, open areas can experience markedly different biotic and abiotic conditions, including a locally increased supply of photosynthetically active radiation (e.g., sunflecks) $[9,10]$. If left undisturbed, these openings constitute ecologically important patches of pronounced tree recruitment and plant growth. Thus, canopy openings support the process of regenerating forest vegetation, and help maintain meaningful biodiversity within the forest ecosystem [11-13]. The altered physical 
structure also modifies spatial movement/habitat selection of fauna [14], influences hydrological processes [6], and affects local carbon cycling [15].

Research on the topic of canopy gaps/openings, defined here as vertical openings within the forest where the sky is visible from $1.3 \mathrm{~m}$ above the ground, has taken place for decades [16,17]. However, ground-based measurements of these features are usually associated with high financial costs and physical effort, which significantly limit the scope of analyses. As a result, applications that rely on field measurements typically cover only small areas of interest, and may not be spatially contiguous. Given these constraints, remote sensing has emerged as the primary source of information on canopy openings [8], though often in an indirect manner. For example, numerous previous studies have used remote sensing to characterize canopy openings as a continuous field, employing metrics such as gap fraction [18-20]) or canopy closure [21-23]. However, in many cases it seems clear that the focus of these analyses is actually the trees themselves rather than the spaces between them. We contend that discrete canopy openings are an essential element of forest structure in their own right. However, they have received considerably less attention in the remote-sensing literature than other attributes more directly associated with trees, such as wood volume, biomass, and leaf area.

While some authors have mapped discrete canopy openings using high-resolution optical imagery [24,25], most recent studies have used light detection and ranging (LiDAR) [26-30], sometimes supplemented with optical data [31,32]. LiDAR is an active remote-sensing technology that is commonly mounted on terrestrial platforms, unmanned aerial vehicles, or piloted aircraft [33] for forest applications. LiDAR pulses can penetrate forest canopies, which enables practitioners to perform detailed terrain characterization and capture accurate measurements of vegetation height, volume, and biomass [34]. Given this ability to generate high-quality horizontal and vertical information, LiDAR has become the benchmark against which other forest-structure assessment technologies are measured.

Digital aerial photogrammetry (DAP) has emerged as a promising and economical alternative to LiDAR in the context of characterizing three-dimensional (3D) forest structure [35], and can produce results that compare favorably with those from LiDAR. While individual measurements may not be as precise, plot metrics extracted from the two datasets have been found to be highly correlated, and can produce comparable models of biomass, basal area, and height [36,37]. Photogrammetry is based on the principle of parallax, which allows image-based algorithms operating in stereo to find tie points and compute $3 \mathrm{D}$ positions relative to a reference datum [38,39]. While photogrammetry is able to achieve positional coordinates based on the matching of just two images, the accuracy and density of DAP point clouds increases with the number of images (and amount of overlap) used in the matching process [35]. The evolution of computing technology has led to the development of more advanced image-matching algorithms, which have improved overall point-cloud quality $[39,40]$.

Table 1 summarizes 19 recent studies comparing LiDAR and DAP for characterizing various aspects of forest structure. Of these, just one [8] has looked explicitly at canopy openings. The vast majority of previous work has focused on terrain or attributes associated directly with trees. This highlights a gap in the literature, and the need for additional comparative studies aimed directly at discrete canopy openings.

Several researchers have examined LiDAR's capabilities in the context of identifying canopy openings, but did not compare them to an alternative DAP dataset [26-28,41]. Even Wallace et al.'s, (2016) comprehensive comparison of LiDAR and DAP data [42] for characterizing forest structure and terrain did not assess individual openings directly. Only White et al.'s unique study [8] performed an explicit comparison of LiDAR and DAP on the topic of "gap detection" of forest-canopy openings between $5 \mathrm{~m}^{2}$ and 2 ha in size in a coastal-temperate rainforest in British Columbia, Canada. The authors used fixed- and variable-height thresholding approaches across a moving window to extract openings from co-registered DAP- and LiDAR-derived canopy height models. They found LiDAR to perform better than DAP, with the latter experiencing large errors of omission. While the study is strong, it took place within a specific biome (coastal-temperate rainforest), and used imagery with relatively low along-track $(60 \%)$ and across-track $(20 \%)$ overlap, producing a modest DAP point density of 
$\sim 12$ points $/ \mathrm{m}^{2}$. These datasets may perform differently in other forest types or with higher-density point clouds.

Table 1. A summary of recent (circa 10 years) studies comparing forest-structure information derived from light detection and ranging (LiDAR) and digital airborne photogrammetry (DAP) reveals the dearth of research assessing canopy openings directly. This is not intended to be an exhaustive list.

\begin{tabular}{|c|c|c|c|c|}
\hline Publication & Location & Forest Type & Forest Attribute & $\begin{array}{c}\text { Investigated } \\
\text { Canopy } \\
\text { Openings? }\end{array}$ \\
\hline $\begin{array}{c}\text { Swinfield et al., } \\
2019 \text { [43] }\end{array}$ & Sumatra, Indonesia & $\begin{array}{l}\text { Lowland tropical } \\
\text { forest }\end{array}$ & $\begin{array}{c}\text { Tree height, } \\
\text { biomass, carbon } \\
\text { density }\end{array}$ & No \\
\hline $\begin{array}{c}\text { Vastaranta et al., } \\
2018[44]\end{array}$ & Finland & Boreal forest & $\begin{array}{l}\text { Forest height, tree } \\
\text { density, tree height }\end{array}$ & No \\
\hline Cao et al., 2019 [45] & Eastern China & $\begin{array}{l}\text { Subtropical planted } \\
\text { forest }\end{array}$ & $\begin{array}{l}\text { Diameter at breast } \\
\text { height, Lorey's } \\
\text { height, basal area, } \\
\text { stem density, } \\
\text { biomass, volume }\end{array}$ & No \\
\hline $\begin{array}{l}\text { Filippelli et al., } \\
2019 \text { [37] }\end{array}$ & Colorado, USA & $\begin{array}{l}\text { Montane } \\
\text { coniferous }\end{array}$ & $\begin{array}{l}\text { Biomass, basal area, } \\
\text { bulk density, } \\
\text { Lorey's height, } \\
\text { maximum height }\end{array}$ & No \\
\hline $\begin{array}{l}\text { Graham et al., } \\
2019 \text { [46] }\end{array}$ & $\begin{array}{l}\text { British Columbia, } \\
\text { Canada }\end{array}$ & $\begin{array}{l}\text { Interior cedar } \\
\text { hemlock }\end{array}$ & Terrain & No \\
\hline $\begin{array}{l}\text { Iqbal et al., } \\
2019 \text { [47] }\end{array}$ & Tasmania & Pine plantation & $\begin{array}{l}\text { Basal area, } \\
\text { stocking, stem } \\
\text { volume }\end{array}$ & No \\
\hline $\begin{array}{l}\text { Swetnam et al., } \\
2018 \text { [48] }\end{array}$ & Arizona, USA & $\begin{array}{l}\text { Chihuahuan desert } \\
\text { scrub, and } \\
\text { semi-arid desert } \\
\text { grassland }\end{array}$ & $\begin{array}{c}\text { Terrain, vegetation } \\
\text { height }\end{array}$ & No \\
\hline $\begin{array}{l}\text { White et al., } \\
2018 \text { [8] }\end{array}$ & $\begin{array}{l}\text { British Columbia, } \\
\text { Canada }\end{array}$ & $\begin{array}{c}\text { Coastal temperate } \\
\text { rainforest }\end{array}$ & Canopy gaps & YES \\
\hline $\begin{array}{l}\text { Pearse et al., } \\
2018 \text { [49] }\end{array}$ & New Zealand & Pine plantation & $\begin{array}{c}\text { Stand height, } \\
\text { density, basal area, } \\
\text { volume }\end{array}$ & No \\
\hline $\begin{array}{c}\text { Fankhauser et al., } \\
2018 \text { [50] }\end{array}$ & Various US states & Various & $\begin{array}{c}\text { Tree counts, tree } \\
\text { height }\end{array}$ & No \\
\hline $\begin{array}{l}\text { Wallace et al., } \\
2016 \text { [42] }\end{array}$ & $\begin{array}{l}\text { Tasmania, } \\
\text { Australia }\end{array}$ & Eucalypt forest & $\begin{array}{c}\text { Terrain, canopy } \\
\text { cover, vertical } \\
\text { canopy profile, } \\
\text { stem location, tree } \\
\text { height }\end{array}$ & No \\
\hline $\begin{array}{l}\text { St-Onge et al., } \\
2015 \text { [51] }\end{array}$ & Quebec, Canada & Boreal forest & $\begin{array}{c}\text { Tree crowns, } \\
\text { species, height }\end{array}$ & No \\
\hline $\begin{array}{l}\text { White et al., } \\
2015 \text { [52] }\end{array}$ & $\begin{array}{l}\text { British Columbia, } \\
\text { Canada }\end{array}$ & $\begin{array}{l}\text { Coastal temperate } \\
\text { rainforest }\end{array}$ & $\begin{array}{l}\text { Tree height, basal } \\
\text { area, volume }\end{array}$ & No \\
\hline Ni et al., 2014 [53] & Main, USA & $\begin{array}{l}\text { Northern } \\
\text { hardwood }\end{array}$ & Canopy height & \\
\hline $\begin{array}{l}\text { Rahlf et al., } \\
2014 \text { [54] }\end{array}$ & Southern Norway & Boreal forest & Timber volume & No \\
\hline
\end{tabular}


Table 1. Cont.

\begin{tabular}{|c|c|c|c|c|}
\hline Publication & Location & Forest Type & Forest Attribute & $\begin{array}{c}\text { Investigated } \\
\text { Canopy } \\
\text { Openings? }\end{array}$ \\
\hline $\begin{array}{c}\text { Vastaranta et al., } \\
2013 \text { [55] }\end{array}$ & Finland & Boreal forest & $\begin{array}{l}\text { Tree volume, } \\
\text { diameter, basal } \\
\text { area, biomass }\end{array}$ & No \\
\hline Gil et al., 2013 [56] & $\begin{array}{l}\text { Canary Islands, } \\
\text { Spain }\end{array}$ & Tropical pine forest & Terrain & No \\
\hline $\begin{array}{l}\text { Bohlin et al., } \\
2012 \text { [57] }\end{array}$ & Sweden & Boreal forest & $\begin{array}{l}\text { Tree height, stem } \\
\text { volume, basal area }\end{array}$ & No \\
\hline $\begin{array}{l}\text { Järnstedt et al., } \\
2012 \text { [58] }\end{array}$ & Finland & Boreal forest & $\begin{array}{l}\text { Mean tree height, } \\
\text { dominant tree } \\
\text { height, basal area, } \\
\text { volume }\end{array}$ & No \\
\hline $\begin{array}{l}\text { St-Onge et al., } \\
2008 \text { [36] }\end{array}$ & $\begin{array}{c}\text { New Brunswick } \\
\text { and Quebec, } \\
\text { Canada }\end{array}$ & $\begin{array}{c}\text { Balsam fir forest, } \\
\text { Boreal forest }\end{array}$ & Canopy height & No \\
\hline
\end{tabular}

\section{Motivation and Objectives}

We require additional studies comparing LiDAR and DAP for mapping discrete canopy openings. In particular, the literature could benefit from work in other forest types, using high-density point clouds, high along- and across-track image overlap, and ground-based reference data. In this study, we aim to contribute such additional insights through experiments in the boreal forest.

Our motivation was to assess the capacity modern $3 \mathrm{D}$ remote-sensing data to characterize forest canopy structure, not to contribute to the disturbance-ecology literature. For that reason, we are interested in canopy openings of any size, including both very small openings and those that are part of large open-ended systems: both of which would fall outside of most classical definitions of "canopy gap" [59]. We did this for two reasons. First, our primary goal was to learn about the respective capabilities of DAP and airborne LiDAR data for capturing discrete forest attributes. As we have indicated, the vast majority of previous studies have focused on trees; relatively few have looked at the spaces between them. Second, it is our contention that the size and ecological impact of canopy openings must be viewed through the lens of an individual species in order to measure their effects. As a result, spatial limitations seemed too arbitrary to be employed in our work.

In order to differentiate our motivations from the those in the canopy-gap literature, we employ the term canopy opening rather than canopy gap, which we perceive to refer to the functional response of openings rather than their physical structure. Our work is designed to provide insights into the nature of emerging DAP technologies, and to help future practitioners make informed decisions on the use of LiDAR and DAP in forested environments. While our findings may inform future studies on canopy gaps, that subject is outside of our current scope.

This study is the first (that we are aware of) in the peer-reviewed literature to compare airborne LiDAR and DAP for characterizing discrete canopy openings in the boreal forest, and one of just a handful to have done so in any biome. In addition, this work employs high-density DAP data extracted from high-overlap ( $80 \%$ along-track and $60 \%$ across-track) aerial photography, which has not been evaluated in previous works

\section{Materials and Methods}

We delineated canopy openings in the boreal forest of northern Alberta, Canada, using canopy height models (CHMs) derived from three different data sources: (i) LiDAR, (ii) DAP, and (iii) a LiDAR/DAP hybrid. In addition to individual datasets, we used the combination of LiDAR and DAP 
to generate a hybrid model, theorizing that a canopy height model that combined the relative strengths of DAP (higher-density point clouds) and LiDAR (more reliable ground detection) could lead to better performance than the DAP model alone. A graphical summary of the workflow used to conduct our experiments is shown in Figure 1. Details are provided in the subsequent subsections.

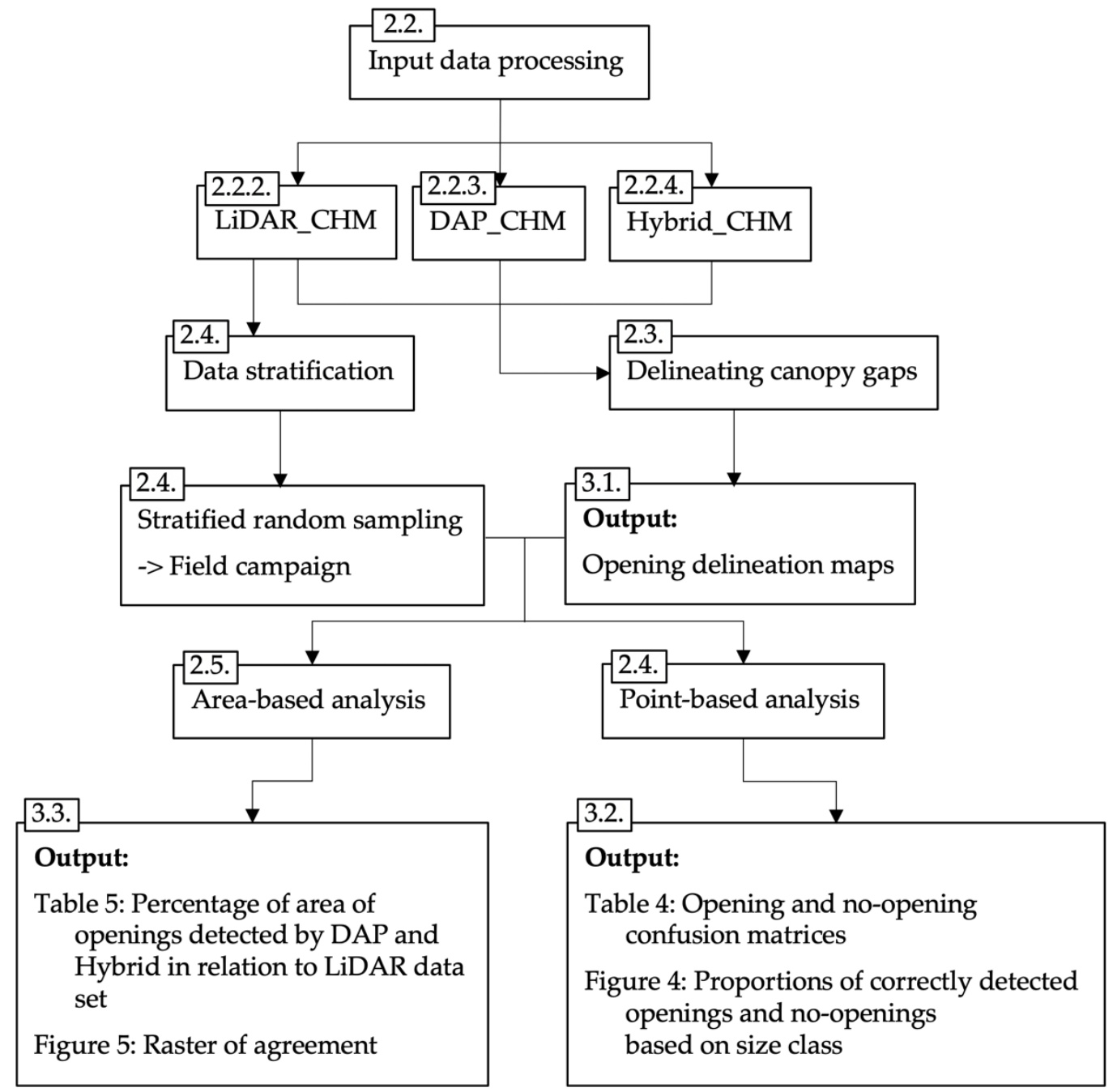

Figure 1. Workflow chart depicting the steps performed in this study, with numbers referring to the corresponding subsections of this paper. Two point clouds-digital aerial photogrammetry (DAP) and light detection and ranging (LiDAR) served as the basis for the derivation of three canopy height model (CHM) alternatives: LiDAR (LiDAR_CHM), DAP (DAP_CHM), and a LiDAR-DAP hybrid (Hybrid_CHM). Evaluation data was generated during a field campaign. Both an area-based as well as a point-based analysis of the resulting opening were performed. Detailed flowcharts for the data processing using LAStools are provided in the Supplementary Material.

\subsection{Study Area}

Our study took place in the boreal forest biome of northern Alberta, Canada: an environment that has been heavily disturbed by petroleum exploration and other forms of resource extraction. This region is in the boreal snow climate, and is characterized by moderately warm, humid summers and cold, dry winters [60]. The average air temperature is below $-10{ }^{\circ} \mathrm{C}$ in January and below $20{ }^{\circ} \mathrm{C}$ in July, with annual precipitation about $445 \mathrm{~mm}$ [60]. The elevation of the study area is approximately $700 \mathrm{~m}$ above mean sea level.

The region is covered by extensive coniferous and mixed-wood forest stands [61]. Black and white spruce (Picea mariana and glauca, respectively), balsam fir (Abies balsamea), trembling aspen 
(Populus tremuloides), balsam polar (Populus balsamifera), jack pine (Pinus banksiana), tamarack (Larix laricina), and paper birch (Betula papyrifera) are the primary tree species in the region [61]. Due to the tall growth structure (canopy height in drier locations ranges between 15 and $30 \mathrm{~m}$ above ground and is considerably lower in the wetlands) and low light availability, undergrowth is not generally pronounced beneath closed canopies, and is typically limited to deciduous shrubs, Sphagnum and feathermosses (Hybnaceae spp.), and lichens (Cladina spp.). The high soil moisture and extensive areas of wetlands-primarily fens and bogs-throughout the region make mosses the ubiquitous understory vegetation layer [61]. Within openings, blueberry (Vaccinium spp.), bearberry (Arctostaphylos uva-ursi), green alder (Alnus viridis), prickly rose (Rosa acicularis), cloudberry (Rubus chamaemorus), raspberry (Rubus idaeus), and Labrador tea (Rhododendron groenlandicum) are widespread.

The specific study area for this research was a $1 \mathrm{~km} \times 1 \mathrm{~km}$ expanse situated $40 \mathrm{~km}$ south of the town of Conklin (Figure 2). It includes natural upland-forest stands, fens, and human disturbances related to bitumen extraction. Due to varying growing conditions, tree density was observed to vary markedly, as were the size and shape of openings; especially between the wet lowlands and the drier uplands. Human-disturbance features including seismic lines (petroleum exploration corridors), pipelines, well sites, and roads occur throughout the study area.

\subsection{Remote Sensing Data Collection and Pre-Processing}

\subsubsection{Remote Sensing Data Collection}

ORTHOSHOP Geomatics Ltd. (OGL) Engineering of Calgary used a piloted aircraft (Cessna 210T) to acquire remote-sensing data for this project over two flights in 2017: one in May (leaf-off conditions) and the other in August (leaf-on conditions). The platform carried a four-band (blue, green, red, and near infrared) optical sensor (Leica RCD30) and a LiDAR instrument (Leica ALS70). The average flying height for both missions was $850 \mathrm{~m}$ above ground level. The projection system/datum used for this survey was NAD83 (CSRS) Universal Transverse Mercator Zone 12N. We installed 250 clearly visible ground control points (GCPs) prior to the first mission. These were left in the field until the completion of the second mission. We recorded the geolocations of these GCPs using a Trimble R8 real-time kinematic (RTK) global navigation satellite system (GNSS) with $8 \mathrm{~mm}$ horizontal and $15 \mathrm{~mm}$ vertical precision.

The purpose of the spring flight (leaf-off conditions) was to obtain data that would deliver the best-possible digital terrain models (DTMs), while the summer flights (leaf-on conditions) were to capture full-canopy digital surface models (DSMs). Unfortunately, the LiDAR sensor experienced technical difficulty during the spring flight, so DAP was the only leaf-off data available for our analysis.

For the optical data, flight lines were designed to deliver a minimum of $80 \%$ endlap and $60 \%$ sidelap, with a ground resolution of $5.5 \mathrm{~cm}$ or less. The raw digital photos were processed into photogrammetric point clouds and four-band digital orthophotos (RGBN) using a structure-from-motion workflow [62] in Pix4D (Version 4.3.27). Both image-based point clouds (leaf-on and leaf-off) had mean point densities greater than 200 points $/ \mathrm{m}^{2}$ for the leaf-on data. Of the 250 GCPs surveyed, we used 100 for georeferencing purposes (point cloud and orthophoto) and reserved the remaining 150 for accuracy assessment. The $X, Y$, and $Z$ accuracy (root mean square error) of the final leaf-off optical products were 5,6 , and $13 \mathrm{~cm}$, respectively. The $X, Y$, and $Z$ accuracy of the leaf-on optical products were 6,6 , and $19 \mathrm{~cm}$ root mean square error (RMSE), respectively. A $1 \mathrm{~km} \times 1 \mathrm{~km}$ sample area was clipped from the larger mission footprint $(5.5 \mathrm{~km} \times 6 \mathrm{~km})$ to match the specific study area for this project.

The discrete-return LiDAR data (2 returns/pulse) were converted to a raw point cloud using inertial and GNSS measurements. Mean point density of the LiDAR data was $\sim 40$ points $/ \mathrm{m}^{2}$ with a mean point spacing of $15 \mathrm{~cm}$. 


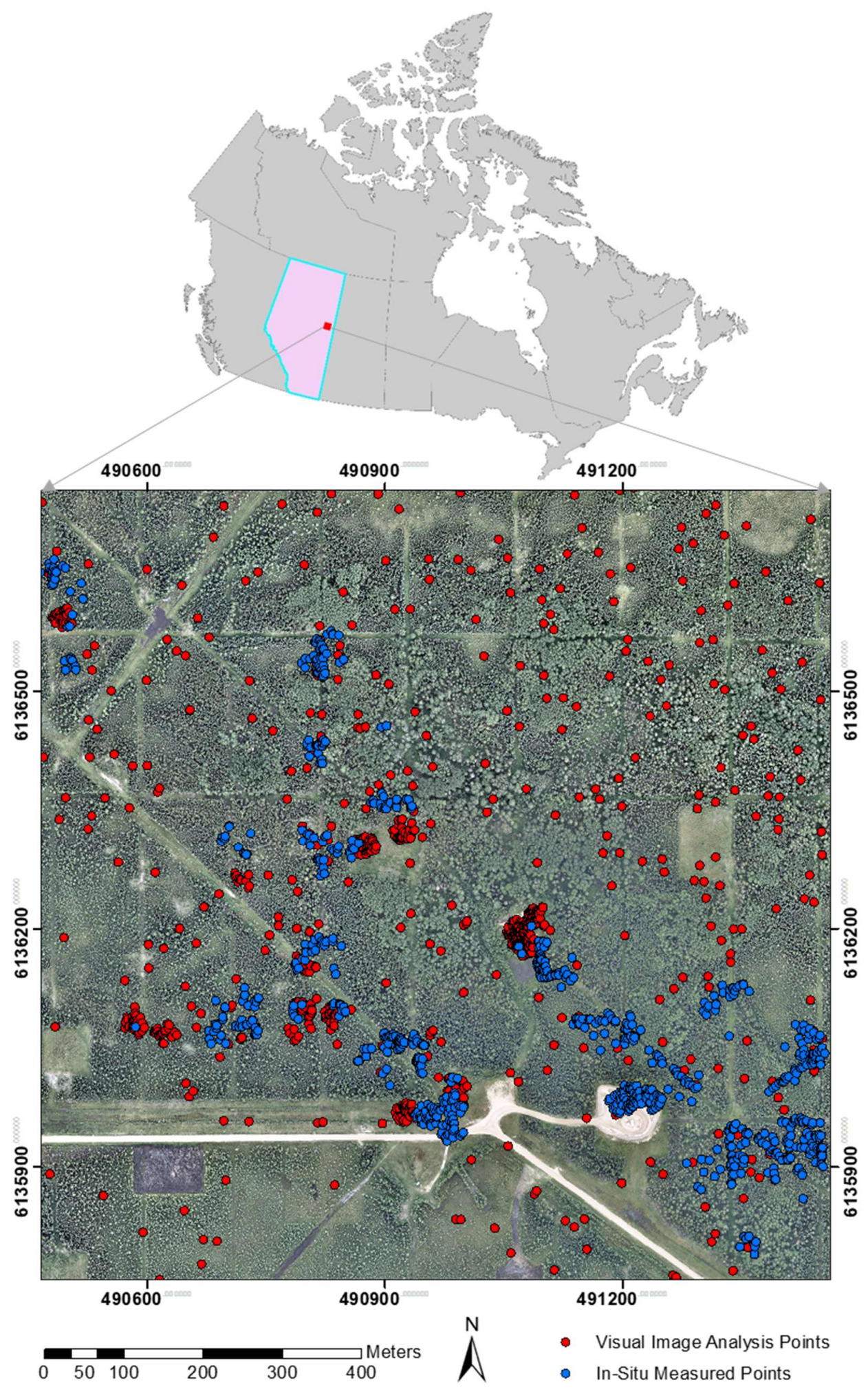

Figure 2. Study area location in Alberta, Canada. Human disturbances related to petroleum extraction-roads, seismic lines (petroleum exploration corridors), and exploration wells-are easily distinguishable from the underlying undisturbed forest. The in-situ reference points are displayed using blue circles and image analysis-based reference points are displayed using red circles. 


\subsubsection{LiDAR-Based CHM}

Leaf-on LiDAR data was used to obtain the LiDAR-based CHM. We used Bentley Microstation with Terrasolid software to remove noise from the raw LiDAR point cloud, and then classified it into ground and non-ground points using LAStools (Version 170802). We next rasterized (20 cm pixels) the ground points into a digital terrain model $\left(\mathrm{DTM}_{\mathrm{LiDAR}}\right)$, and the first-return points into a digital surface model $\left(\mathrm{DSM}_{\mathrm{LiDAR}}\right)$. Finally, a canopy height model $\left(\mathrm{CHM}_{\mathrm{LiDAR}}\right)$ was obtained by subtracting the DTM $\mathrm{LiDAR}_{\mathrm{L}}$ from the $\mathrm{DSM}_{\mathrm{LiDAR}}$.

\subsubsection{DAP-Based CHM}

We used LAStools to classify the leaf-off DAP point clouds into ground and non-ground points.

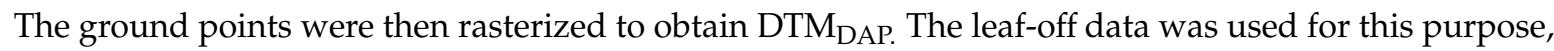
under the assumption that ground can be better modeled under leaf-off conditions. We then rasterized the leaf-on DAP points (all points) to obtain DSM ${ }_{\text {DAP }}$. Finally, we subtracted the DTM ${ }_{D A P}$ from the $\mathrm{DSM}_{\mathrm{DAP}}$ to create a $\mathrm{CHM}_{\mathrm{DAP}}$. All DAP-derived products had a spatial resolution of $20 \mathrm{~cm}$, matching those from the LiDAR.

\subsubsection{Hybrid CHM}

LiDAR sensors have better canopy penetration abilities than DAP, and are therefore better suited to modeling the terrain [42]. Hence, we produced a hybrid $\mathrm{CHM}\left(\mathrm{CHM}_{\mathrm{Hybrid}}\right)$ using the $\mathrm{DSM}_{\mathrm{DAP}}$

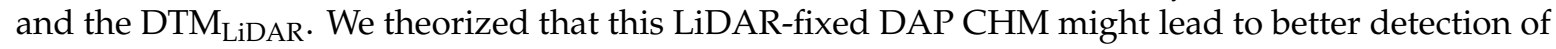
canopy openings, given the reliance on fixed-height thresholds for delineating canopy openings, as described in Section 2.3, and the high-density point cloud produced by DAP.

\subsection{Delineating Canopy Openings}

We used a fixed-height approach to extract canopy openings from each of the experimental CHMs. The purpose of this processing step was to separate low-lying and regrowth vegetation from established canopy forming vegetation. While some studies have used variable-height approaches for this task, where the threshold varies as a function of stand height [e.g., 8], we elected for the more parsimonious fixed-height approach. This decision was primarily designed to simplify the job of field personnel.

Given the presence of short, stunted trees within the large wetland portions of our study area, we set a relatively low canopy threshold of $1.3 \mathrm{~m}$. Thus, vegetation below $1.3 \mathrm{~m}$ was considered non-canopy vegetation. Vegetation above this threshold was considered established vegetation, as it is mostly safe from ungulates [54]. We made no distinction between trees and other forms of vegetation, such as shrubs. The three CHMs (LiDAR, DAP, and hybrid) were converted to binary opening/no-opening maps using this threshold (i.e., $\mathrm{CHM}>1.3=$ no-opening and $\mathrm{CHM} \leq 1.3=$ opening).

\subsection{Validating Canopy Openings_-Point-Based Analysis}

We used a multi-stage sampling approach to create a reference dataset suitable for validating the accuracy of the three canopy-opening maps. First, we divided the study area into two strata, disturbed and undisturbed, since the patterns of openings within these two classes across the study area were observed to be fundamentally different. Disturbed areas included roads, seismic lines, and well sites, which we delineated manually using the $5.5-\mathrm{cm}$ orthophotos. Undisturbed areas were defined as the natural areas outside of these anthropogenic features. It is important to note that many of the disturbed portions of our study area supported vegetation taller than $1.3 \mathrm{~m}$, which would be subsequently classified as no-opening.

The second sampling stage involved delineating a stratum describing canopy-opening size. We defined five opening-size classes to provide categories that could be distinguished unambiguously by personnel in the field: 
Opening class 0 : No opening (sky above $1.3 \mathrm{~m}$ obscured by vegetation)

Opening class 1: $>0$ to $4 \mathrm{~m}^{2}$

Opening class 2: $>4$ to $20 \mathrm{~m}^{2}$

Opening class 3: $>20$ to $200 \mathrm{~m}^{2}$

Opening class 4: $>200 \mathrm{~m}^{2}$.

Sample size ( $n$ ) was calculated following Kershaw et al. [63], who described an equation designed to incorporate factors of variability $(C V)$ and allowable error $(E)$ :

$$
n=t^{2} C V^{2} / E^{2}
$$

where $t$ is the probability level (Student's $t$ value) implied by the associated $E$ value, and $C V$ is the coefficient of variation of canopy openings across the study area. We used an $E$ value of $20 \%$ (confidence level $80 \%$ ), which resulted in a $t$ value of 1.3 . The variability of openings and no-openings across the study area $(\mathrm{CV})$ was estimated using the canopy-opening map produced with the $\mathrm{CHM}_{\mathrm{LiDAR}}$ layer. We selected $\mathrm{CHM}_{\mathrm{LiDAR}}$ for this purpose given its status in the literature and the experience of White et al. [8], who found it to be a good source of canopy-opening information.

Equation (1) produced a recommended sample size of 1835, which we distributed proportionally across the study area using ArcMAP (Version 10.5). The distribution of these sample points is summarized in Table 2.

Table 2. Distribution of validation samples across opening size class and disturbance regime. Equation (1) suggested higher values for Class 0 (both in disturbed and in undisturbed areas) and a smaller number for Class 2 in undisturbed areas. All three values were adjusted for feasibility and statistical robustness, respectively.

\begin{tabular}{ccc}
\hline & \multicolumn{2}{c}{ Number of Samples } \\
\hline Opening Class & Disturbed & Undisturbed \\
\hline 0 & 100 & 300 \\
1 & 116 & 102 \\
2 & 36 & 30 \\
3 & 69 & 104 \\
4 & 396 & 582 \\
Total & 717 & 1118 \\
\hline
\end{tabular}

We used a combination of in-situ measurements (879 points) and visual image analysis (956 points) to collect opening-class reference attributes associated with the 1835 locations in our sample. We elected to perform as many in-situ observations as possible, and used cluster sampling to maximize the efficiency of personnel in the field. For safety and logistical reasons, field sampling was limited to within $30 \mathrm{~m}$ of 84 previously existing study sites, which were being visited by researchers working on a related project. These study sites were carefully established (using a stratified-random sampling technique) to account for the structural and functional variability present within the study area. The field campaign was executed in July 2018, and represents leaf-on conditions.

Field personnel used an RTK GNSS with a horizontal accuracy of $10 \mathrm{~cm}$ or better to navigate to the in-situ sample points. Upon reaching a sample location, the surveyor checked if the sky was visible at $1.3 \mathrm{~m}$ above ground to determine if the location was an opening or no-opening. If it was an opening, the surveyor also assigned a class label to the opening to the best of her judgement. A photographic record of each site was made with a vertically oriented camera pointed at the sky at $1.3 \mathrm{~m}$; representative photographs from each class are shown in Figure 3. Field calls were made by the same surveyor throughout the study for consistency. We visited 879 field locations for in-situ measurements.

Visual image analysis was performed on the remaining 956 points using orthophotography and the LiDAR CHM. Once again, image calls were made by the same surveyor for consistency. 
We acknowledge that using LiDAR data in our visual assessment had the potential to bias our reference data. However, a preliminary assessment of LiDAR accuracy using the 879 in-situ points produced an overall accuracy of $97.8 \%$. This provided us with confidence in being able to use LiDAR data as a visual reference-as well as orthophotography—for supplementary image-based samples.
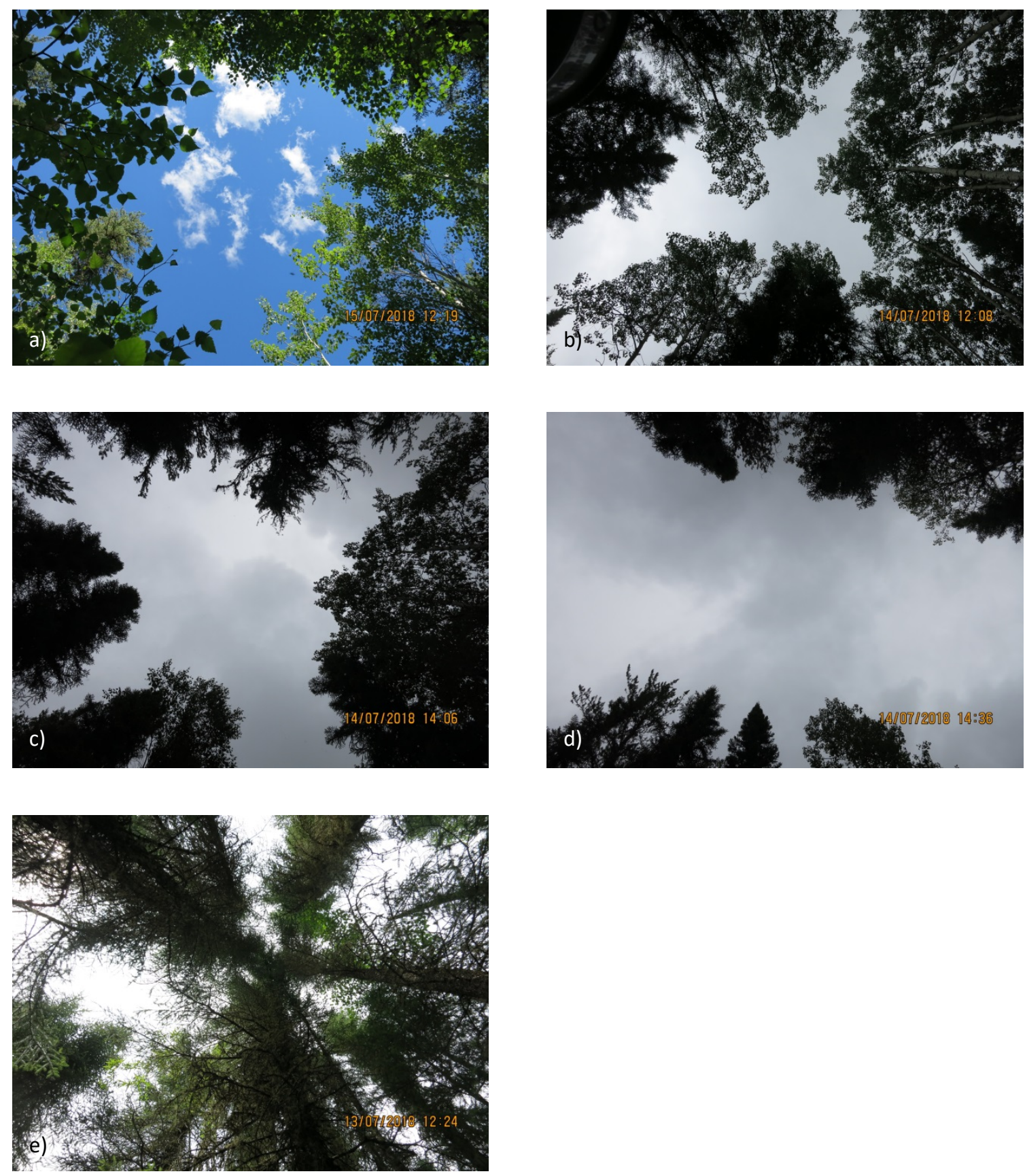

Figure 3. Vertical photography displaying representative samples of openings from classes 1 (a), 2, (b), 3 (c), and 4 (d), as well as no-opening class 0 (e).

Our in-situ sampling design (cluster sampling) led to concerns regarding spatial autocorrelation in the reference data (Figure 2). To address this, we inspected the range of a semi-variogram created

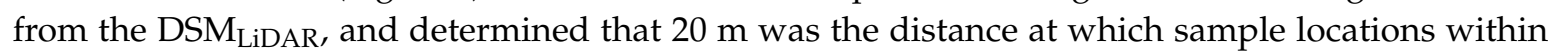
our study area were no longer spatially autocorrelated. Consequently, we subdivided our full set of validation points into 100 random subsets. Within each subset, individual samples were kept least $20 \mathrm{~m}$ apart. This was achieved with the following steps: 
1. Identify and isolate points that do not have a neighboring point within a $20 \mathrm{~m}$ distance.

2. Randomly select one point from the remaining points. Identify all remaining points within a $20 \mathrm{~m}$ distance of this point and remove them from the list.

3. From the remaining points in the list, select another random point. Identify all the points within a $20 \mathrm{~m}$ distance of this point and remove them from the list.

4. Repeat step 3 until the list is empty.

5. Add the randomly selected samples (steps 2-4) and the isolated samples (step 1) together to obtain a complete set of spatially uncorrelated samples.

These steps were repeated 100 times to generate 100 subsets of random samples. The sample distribution of these 100 subsets across classes is presented in Table 3.

Table 3. Mean (of 100 subsets) distribution of downsized (from original) samples across classes. This downsizing was performed to remove spatial autocorrelation.

\begin{tabular}{ccccccc}
\hline & Class 0 & Class 1 & Class 2 & Class 3 & Class 4 & Total \\
\hline Mean Number of Samples & 207 & 32 & 19 & 25 & 73 & 358 \\
Standard Deviation & 3.86 & 3.68 & 2.75 & 3.38 & 4.07 & 4.81 \\
\hline
\end{tabular}

This exercise allowed us to obtain an average of 358 unbiased samples in each sampling round. These samples were observed to be evenly distributed across opening classes. The low standard deviation values in Table 3 indicate that the number of samples generated in each run did not deviate from the mean by a large margin. Consequently, the average results of these 100 sample sets were used in the remaining sections of this paper for analyses and accuracy assessments.

\subsection{Examination of Opening Characteristics-Area-Based Analysis}

While the point-based validation exercise (Section 2.4) provided important information on the ability of the three candidate products to detect canopy openings and no-openings observed at single points, it did not explicitly compare the resulting scaled-up aerial estimates summed across the whole study area. As a result, we performed a second analysis that compared the total area of openings measured by LiDAR with those detected by each of the two DAP-based products.

To further investigate this, we also compared the area of individual openings produced by DAP/hybrid with that of LiDAR. To do so, we converted each LiDAR-derived opening into a polygon feature and attributed it with a corresponding class. Then, the LiDAR polygons were overlaid onto the DAP and hybrid CHMs (Figure 4). In this manner, we could quantify the percent area of the LiDAR-based opening polygons that were identified by DAP and hybrid. For visual analysis, we also produced a raster of agreement, which communicates the number of datasets documenting any given opening.

\subsection{Examination of the Value of DAP in Measuring Height}

In addition to experiments designed to compare the capacity of the experimental datasets to characterize canopy openings, we also conducted a simple analysis to assess the value of the hybrid model in estimating canopy height, compared to the DAP model. To do so, we used the LiDAR-measued heights as reference and created difference maps for DAP $\left(\mathrm{CHM}_{\mathrm{LiDAR}}-\mathrm{CHM}_{\mathrm{DAP}}\right)$ and hybrid $\left(\mathrm{CHM}_{\mathrm{LiDAR}}-\mathrm{CHM}_{\mathrm{Hybrid}}\right)$ models. Subsequently, we classified the difference maps into five classes ( -30 to $-10 \mathrm{~m},-10$ to $-2 \mathrm{~m},-2$ to $2 \mathrm{~m}, 2$ to $10 \mathrm{~m}$, and 10 to $28 \mathrm{~m}$ ) for a visual assessment. 


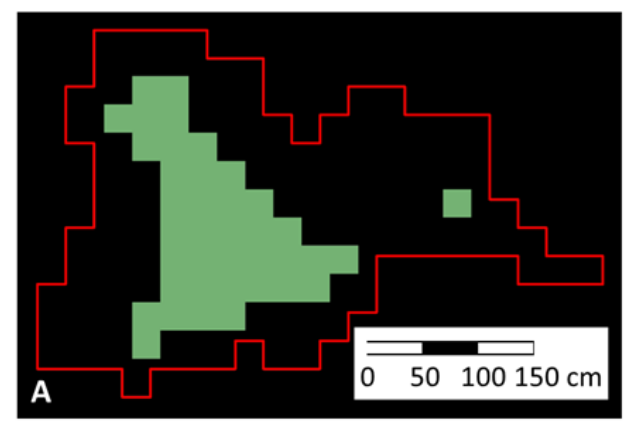

DAP Opening

$\neg$ LiDAR Opening Polygon

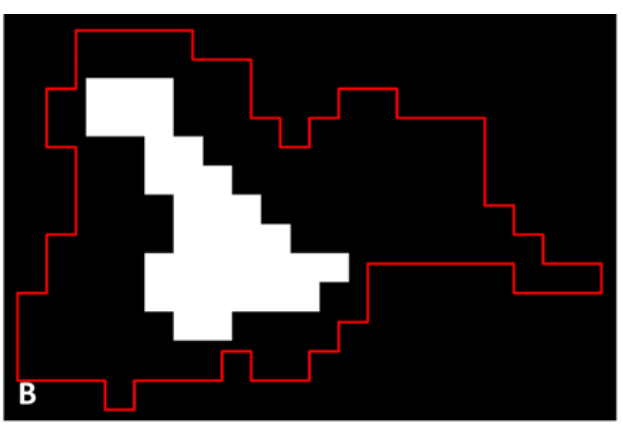

Hybrid Opening

Hybrid No-Opening

$\square$ LiDAR Opening Polygon

Figure 4. An example of determining the percent area of a LiDAR polygon identified by DAP (green) and hybrid (white) data. Panel A represents LiDAR polygon over DAP opening map. Panel B represents LiDAR polygon over hybrid opening map. The area of the opening pixels was compared to the area identified as openings by the LiDAR polygons.

\section{Results}

\subsection{Opening Maps}

Figure 5 presents the three derived maps delineating canopy openings and no-openings

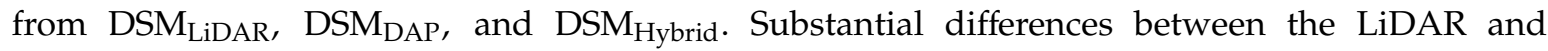
$\mathrm{DAP} /$ hybridyHyH maps are apparent, especially in terms of number of openings and the total area classified as opening. However, there is very little visible difference between DAP and hybrid.

\subsection{Point-Based Analysis}

When the opening maps were evaluated against our point-based validation data (Table 4), LiDAR was found to produce the highest overall accuracy: 94\%. DAP and hybrid data had overall accuracies of $77 \%$ and $78 \%$, respectively. A Z-test revealed that all these accuracies were significantly different from each other $(p<0.05)$ at the $95 \%$ confidence level. Table 4 further reports on errors of omission and commission, which can be translated into underestimation and overestimation of openings. LiDAR tended to slightly underestimate the true number of canopy openings ( $13 \%$ errors of omission; $1 \%$ errors of commission), and correspondingly overestimate the number of no-openings ( $0 \%$ errors of omission; $9 \%$ errors of commission). The same error pattern-underestimation of openings; overestimation of no-openings-was observed in the DAP and the hybrid datasets, though more exaggerated.

Table 4. Summary of opening and no-opening detection confusion matrices: mean overall accuracies, and errors of omission and commission. One-hundred sets of uncorrelated samples were used to produce these statistics.

\begin{tabular}{|c|c|c|c|c|c|c|}
\hline \multirow[b]{2}{*}{ Method } & \multirow{2}{*}{$\begin{array}{c}\text { Overall } \\
\text { Accuracy * } \\
(\%)\end{array}$} & \multicolumn{2}{|c|}{ Opening } & \multicolumn{2}{|c|}{ No-Opening } & \multirow[b]{2}{*}{ Kappa } \\
\hline & & $\begin{array}{l}\text { Omission } \\
\text { Error (\%) }\end{array}$ & $\begin{array}{l}\text { Commission } \\
\text { Error (\%) }\end{array}$ & $\begin{array}{l}\text { Omission } \\
\text { Error }(\%)\end{array}$ & $\begin{array}{l}\text { Commission } \\
\text { Error }(\%)\end{array}$ & \\
\hline LiDAR & 94.4 & 12.3 & 0.5 & 0.3 & 8.6 & 0.88 \\
\hline DAP & 77.4 & 53.7 & 0.1 & 0.0 & 28.1 & 0.50 \\
\hline Hybrid & 77.8 & 52.6 & 0.1 & 0.0 & 27.7 & 0.51 \\
\hline
\end{tabular}

* Overall-accuracy statistics includes data from all classes, including the highly accurate no-openings category.

Figure 6 presents relative-detection accuracies within different opening-size classes. Accuracies were observed to rise for all three data sets as opening-size class increased. No-openings (Class 0 ) were detected at close to $100 \%$ by all three approaches. LiDAR-detection results were notably higher than those produced by DAP and hybrid data sets for all four classes of openings. While DAP and hybrid 
CHMs were found to be reasonably able to detect openings larger than $200 \mathrm{~m}^{2}$ (Class 4; $>70 \%$ ), small openings $<20 \mathrm{~m}^{2}$ had very low $(<20 \%)$ detection rates. LiDAR, on the other hand, showed detection rates $>70 \%$ for all size classes and $>90 \%$ for openings larger than $20 \mathrm{~m}^{2}$ (Classes 3 and 4 ). On an average, overall opening detection accuracy of LiDAR, DAP and hybrid models were $87 \%$, 46\%, and $47 \%$ respectively (excluding no-opening samples).

\section{LiDAR}

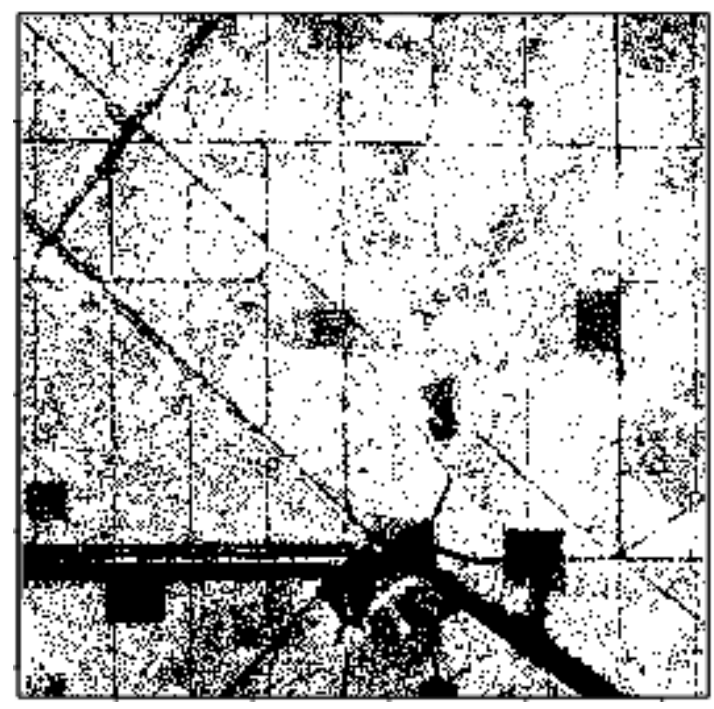

DAP

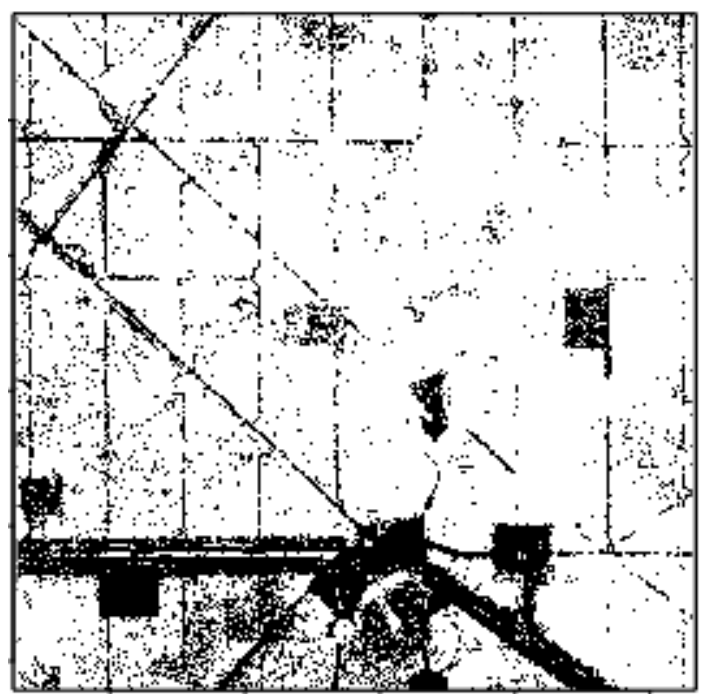

Hybrid

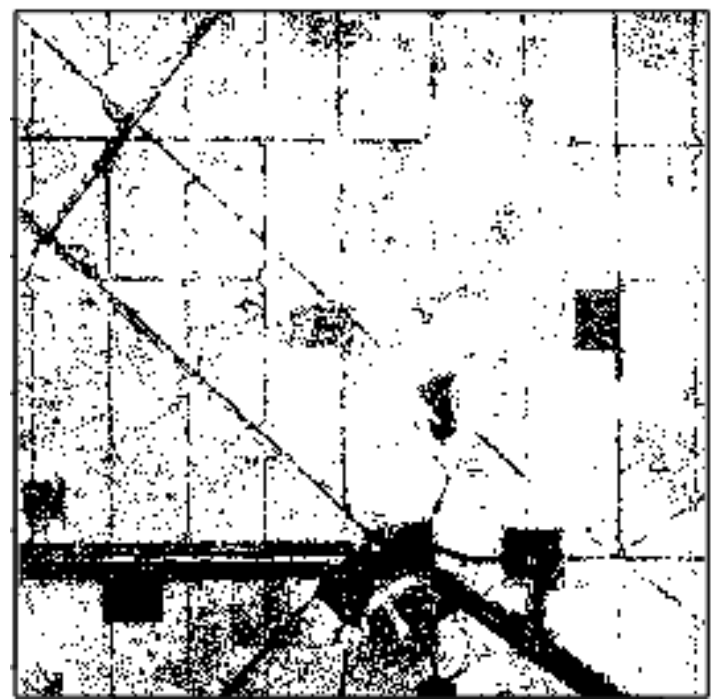

Figure 5. Maps showing canopy opening delineations for each approach. Openings are depicted in black, areas classified as no-openings are depicted in white. Opening delineations were derived from $\mathrm{CHM}_{\mathrm{LiDAR}}\left(\right.$ top), $\mathrm{CHM}_{\mathrm{DAP}}$ (lower left), and $\mathrm{CHM}_{\text {Hybrid }}$ (lower right). 


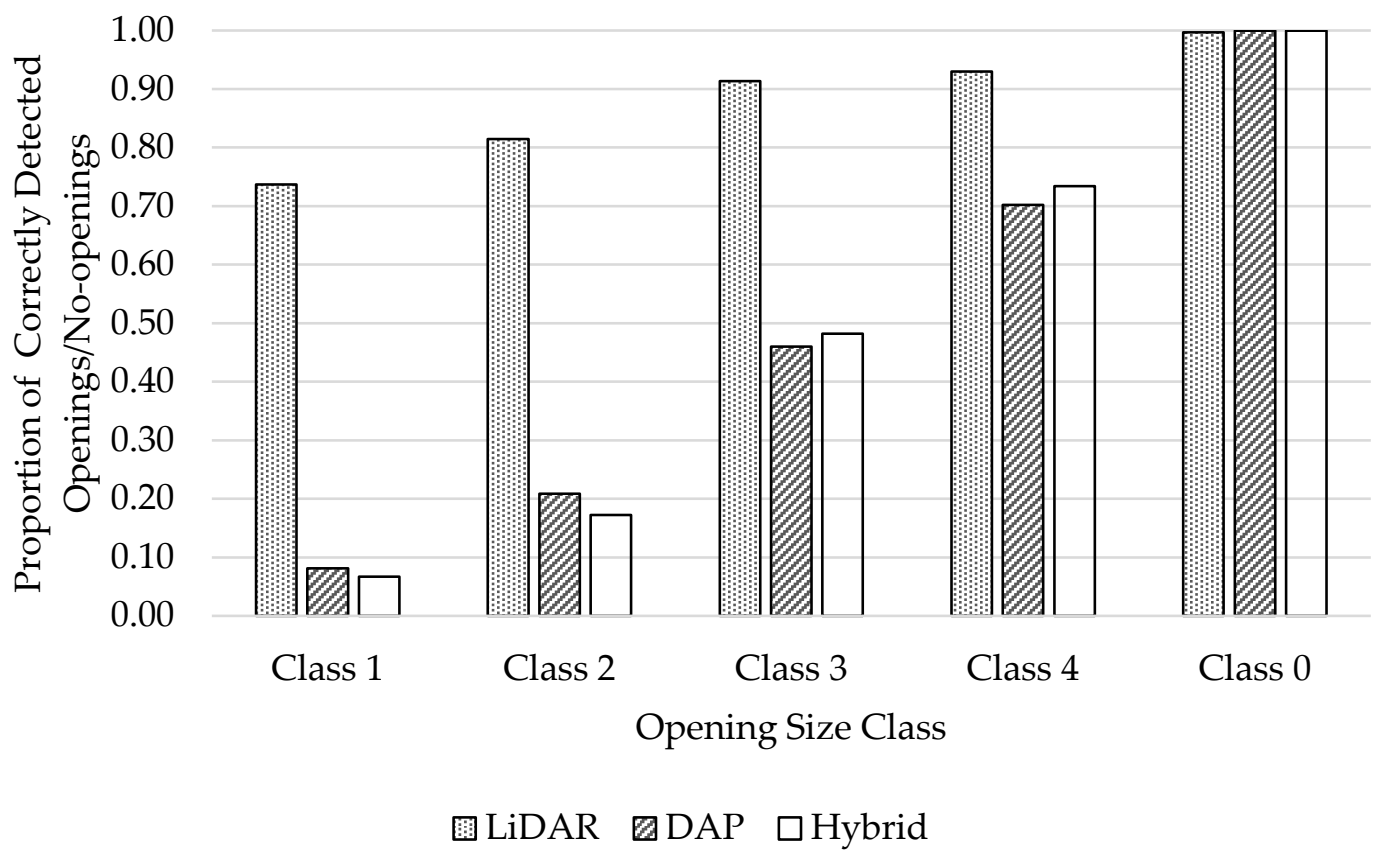

Figure 6. Results of canopy opening and no-opening detection presenting the proportion of correctly detected openings, relative to their size class. Class 0 is no-opening, Class 1 is openings $>0-4 \mathrm{~m}^{2}$, Class 2 is openings $>4-20 \mathrm{~m}^{2}$, Class 3 is openings $>20-200 \mathrm{~m}^{2}$, and Class 4 is openings $>200 \mathrm{~m}^{2}$. The evaluation of size class-dependent detection rates is based on the average of 100 sample runs.

\subsection{Area-Based Analysis}

The total area of openings detected by the LiDAR dataset was $245,920 \mathrm{~m}^{2}$, which is equivalent to about $33 \%$ of the study area. DAP and hybrid data estimated considerably smaller total areas of openings: $152,470 \mathrm{~m}^{2}$ and $159,848 \mathrm{~m}^{2}$, respectively. This represents just $62 \%$ (DAP) and $65 \%$ (hybrid) of the amount of openings detected by LiDAR.

Table 5 provides a more detailed assessment of our area-based analysis, with openings grouped by class and percentage of area detected. The vast majority $(96 \%$ and $97 \%)$ of the very small $\left(0-4 \mathrm{~m}^{2}\right)$ openings recorded by LiDAR were not detected at all in the DAP or hybrid datasets. Of the $\sim 4 \%$ that were detected by DAP and hybrid, about half $(1.8 \%)$ covered less than $20 \%$ of the polygon areas. Less than $0.5 \%$ of the very small openings detected by LiDAR were represented completely $(80-100 \%$ of the area covered) by DAP and hybrid. This pattern of DAP and hybrid either missing canopy openings detected by LiDAR or delineating just a portion of their area improved steadily as opening size increased, to the point where all of the very large $\left(>200 \mathrm{~m}^{2}\right)$ openings detected by LiDAR were also delineated by DAD and hybrid, though never as thoroughly (only $\sim 4-8 \%$ of the areas fully depicted).

Table 5. Percent area of openings detected by DAP and hybrid datasets with reference to the LiDAR dataset.

\begin{tabular}{|c|c|c|c|c|c|c|c|c|}
\hline \multirow{2}{*}{ 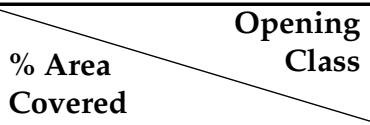 } & \multicolumn{2}{|c|}{$0-4 \mathrm{~m}^{2}$} & \multicolumn{2}{|c|}{$4-20 \mathrm{~m}^{2}$} & \multicolumn{2}{|c|}{$20-200 \mathrm{~m}^{2}$} & \multicolumn{2}{|c|}{$>200 \mathrm{~m}^{2}$} \\
\hline & DAP & Hybrid & DAP & Hybrid & DAP & Hybrid & DAP & Hybrid \\
\hline Undetected & 96.4 & 97.3 & 44.5 & 43.7 & 7.7 & 8.4 & 0.0 & 0.0 \\
\hline$<20 \%$ & 1.8 & 1.8 & 35.4 & 33.7 & 24.7 & 19.7 & 0.0 & 0.0 \\
\hline $20-40 \%$ & 0.7 & 0.5 & 13.4 & 15.0 & 40.0 & 38.0 & 10.2 & 6.1 \\
\hline $40-60 \%$ & 0.3 & 0.2 & 5.6 & 6.3 & 21.6 & 25.6 & 34.7 & 26.5 \\
\hline $60-80 \%$ & 0.2 & 0.1 & 1.0 & 1.1 & 5.8 & 7.7 & 51.0 & 59.2 \\
\hline $80-100 \%$ & 0.6 & 0.2 & 0.2 & 0.3 & 0.3 & 0.6 & 4.1 & 8.2 \\
\hline
\end{tabular}


Figure 7 shows the raster of agreement displaying the spatial overlap among all three opening maps. Large openings on roads, clear cuts, conventional seismic lines, and water bodies were consistently detected by all three approaches (pixels displayed in green). Higher disagreement was found among smaller openings (yellow, orange, and red pixels). Abundant orange dots found throughout the image indicate that many small openings were captured only by the LiDAR dataset. These graphical observations comply with the numeric results presented previously.

\section{Raster of agreement}
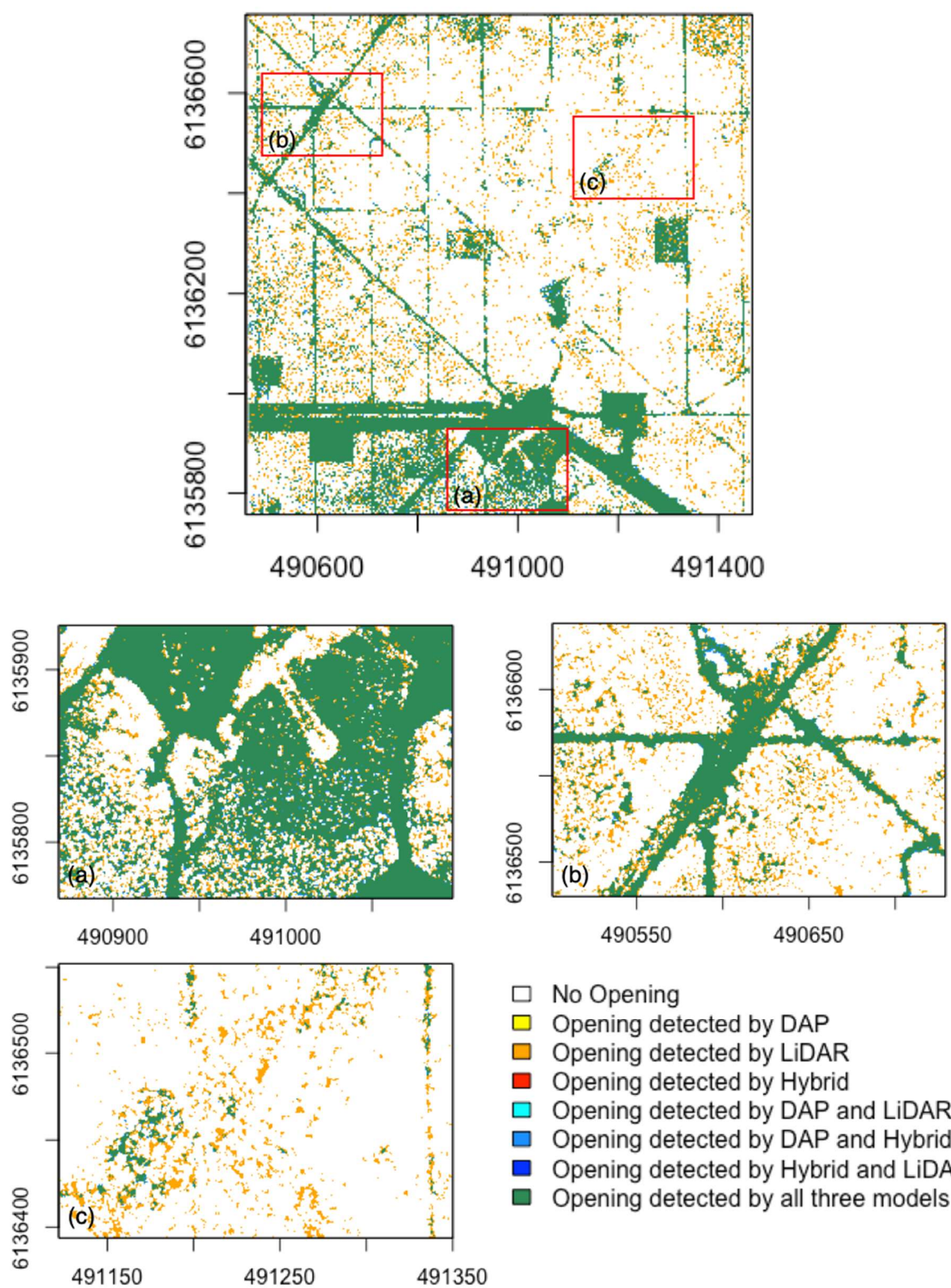

$\square$ No Opening

$\square$ Opening detected by DAP

$\square$ Opening detected by LiDAR

$\square$ Opening detected by Hybrid

$\square$ Opening detected by DAP and LiDAR

$\square$ Opening detected by DAP and Hybrid

- Opening detected by Hybrid and LiDAR

$\square$ Opening detected by all three models

Figure 7. Raster of agreement for all three opening detection approaches, presented for the entire study area (a) and two excerpts, showing detailed distributions of agreement (b) and (c). The legend shows the number and kind of opening maps agreeing on the classification of a pixel as opening. Pixels with the value " 0 " are not classified as opening by any approach. 


\subsection{Value of the Hybrid Model-CHM $M_{H y b r i d}$ vs. $C H M_{D A P}$ Relative to $C H M_{L i D A R}$}

There was no major difference in results obtained by the DAP and hybrid datasets in identifying and delineating openings and no-openings (Sections 3.1 and 3.2), suggesting that there is little value in integrating LiDAR and DAP for this purpose. In retrospect this is understandable, since both DAP and hybrid techniques used the same DSM, which is the controlling layer for binary opening/no-opening detection. However, our assumption was that the added value of the hybrid model would be in estimating canopy height, as it uses a better DTM (from LiDAR). To examine this assumption, we subtracted $\mathrm{CHM}_{\mathrm{DAP}}$ and $\mathrm{CHM}_{\mathrm{Hybrid}}$ from $\mathrm{CHM}_{\mathrm{LiDAR}}$ and analyzed the resulting differential images (Figure 8). Figure 8a shows large, solid patches of high divergence (illustrated in shades of turquoise and dark brown) in the differential image between $\mathrm{CHM}_{\mathrm{DAP}}$ and $\mathrm{CHM}_{\mathrm{LiDAR}}$. These patterns are the result of the overestimation of ground height and underestimation of vegetation height by digital photogrammetry [64]. While $70 \%$ of all pixels of $\mathrm{CHM}_{\mathrm{DAP}}$ were within the $+/-2 \mathrm{~m}$ range of $\mathrm{CHM}_{\mathrm{LiDAR}}$ canopy heights, this proportion increased to $81 \%$ when comparing $\mathrm{CHM}_{\mathrm{Hybrid}}$ and $\mathrm{CHM}_{\text {LiDAR. }}$. Root mean square errors were $3.6 \mathrm{~m}$ and $3.1 \mathrm{~m}$ for $\mathrm{CHM}_{\mathrm{DAP}}$ and $\mathrm{CHM}_{\text {Hybrid, }}$, respectively. This simple analysis provides clear evidence that canopy height estimation by the hybrid dataset is more consistent than the DAP dataset. However, this did little to assist in the detection of canopy openings.
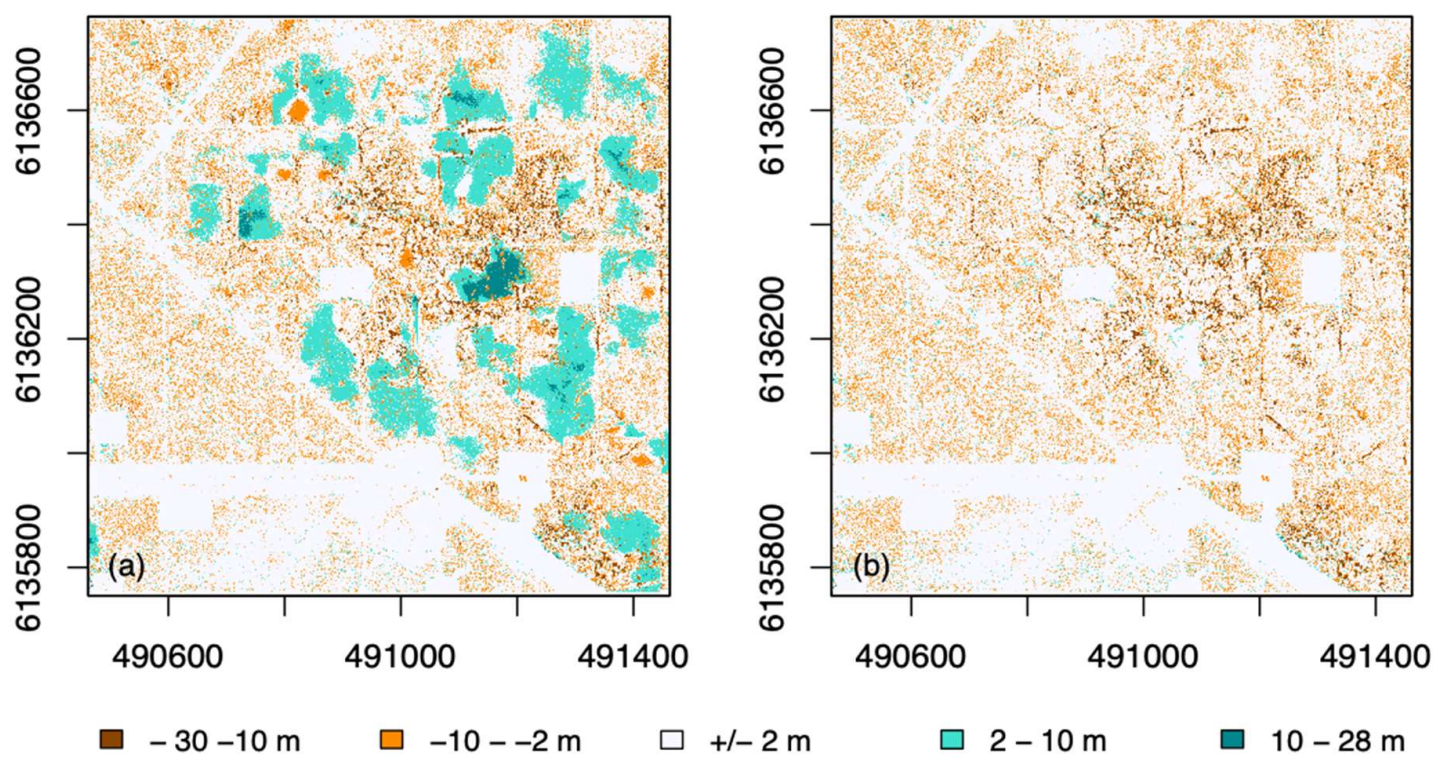

Figure 8. Differential images of: (a) $\mathrm{CHM}_{\mathrm{DAP}}$ and (b) $\mathrm{CHM}_{\mathrm{Hybrid}}$, each compared to $\mathrm{CHM}_{\mathrm{LiDAR}}$. (a) shows large clusters of high divergence from the $\mathrm{CHM}_{\mathrm{LiDAR}}$, depicted in turquoise. These conglomerations are missing in (b), showing the improvement made possible by using a LiDAR-derived DTM.

\section{Discussion}

We examined the capability of three different 3D datasets to map canopy openings in the boreal forest: LiDAR, DAP, and hybrid. As expected, the LiDAR dataset exhibited the highest accuracy measures when compared to the validation data, both in terms of opening detectability $(73 \%, 81 \%$, $91 \%$, and $93 \%$ for classes 1 through 4 , respectively) and overall accuracy $(94 \%$, which includes the no-opening class). The DAP and hybrid approaches produced much more modest results, both for opening detectability (DAP $8 \%, 21 \%, 46 \%$, and $70 \%$; hybrid $7 \%, 18 \%, 48 \%$, and $73 \%$ for classes 1 through 4 , respectively) and overall accuracy ( $77 \%$ and $78 \%$ for DAP and hybrid, respectively). Upon closer inspection, DAP and hybrid data sets were found to perform worst in high-density tree stands, where openings are generally small. This can be seen in Figure 9, where the DAP data set omits many small openings. When we stratified the results by opening size, very large $\left(>200 \mathrm{~m}^{2}\right)$ openings and no-opening areas were mapped reliably by both DAP and hybrid. As a result, we recommend these technologies as a good, low-cost solution for mapping large openings, such as those produced by 
windthrow, fire, and many anthropogenic disturbances. However, LiDAR's superior accuracy with smaller openings makes it the preferred technology for mapping the complete range of openings encountered in the boreal forest, which includes very small openings.

ALS
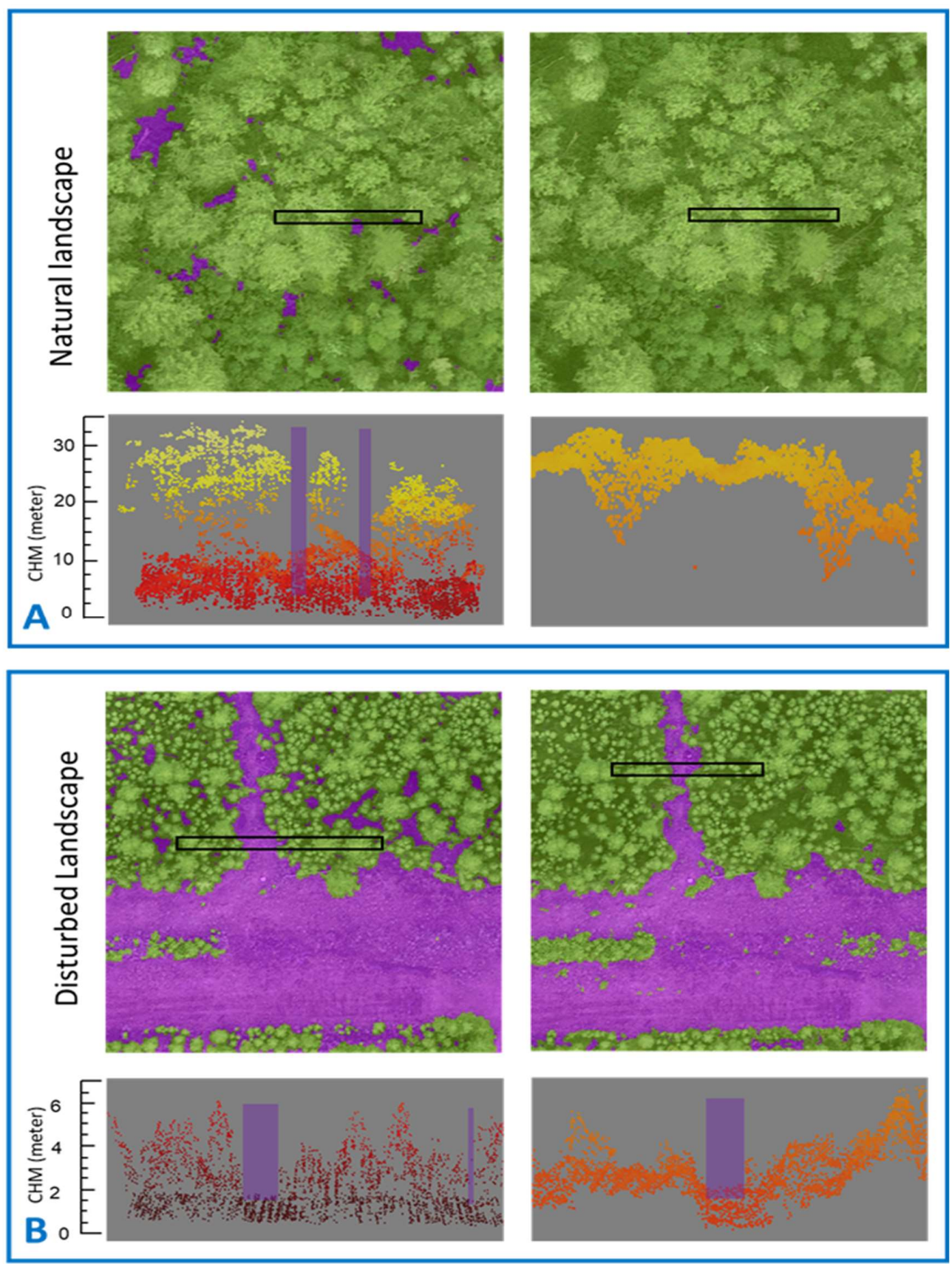

Figure 9. A visual comparison between LiDAR and DAP opening map segments in the study area. In the map segments, the purple areas represent pixels classified as opening by the respective approach, whereas the trees visibility is enhanced by using a green overlay. Black rectangles in each map segments represent an area for which corresponding vertical profiles of original elevation data (point cloud) are displayed below. Figure 6A displays a sample area in natural landscape where small openings are picked up by LiDAR (left) but not by DAP (right). Figure 6B represents a sample area in disturbed landscape where roads and seismic lines are more or less perfectly detected by both techniques. However, the LiDAR data identify other smaller openings in the surrounding landscape that DAP does not identify. 
This propensity of DAP-derived CHMs to miss smaller openings seems ill-matched to the very high density of the DAP point cloud we employed $\left(>200 \mathrm{pts} / \mathrm{m}^{2}\right)$, though it mirrors the observations of White et al. [8] and Zielewska-Büttner et al. [65]. The omission of small openings might be due to a number of factors, including occlusions, shadows, and tree sway between photographs, as reported previously [8]. However, our photography was acquired in light-wind and strong, diffuse-light conditions specifically designed to reduce these known limitations. Even though our DAP data set was acquired with much higher image acquisition overlap and point density ( $80 \%$ along-track, $60 \%$ across-track and 270 points $\left./ \mathrm{m}^{2}\right)$ than previous studies, e.g., White et al. [8] (60\% along-track and $20 \%$ across-track and 12.27 points $/ \mathrm{m}^{2}$ ), the DAP data showed a significant shortcoming in detecting smaller openings. Interestingly, we found canopy openings—both large and small—to be easily observed using the same photoset that underlies the DAP data, when viewed in a softcopy environment. Our suspicion is that the photogrammetric data was degraded by the structure-from-motion workflow. Previous authors have noted the difficulty of detecting individual trees automatically, and the propensity of structure-from-motion workflows to confuse tie points in such complex scenes [40]. In addition to observing best practices related to flight parameters, image overlap, and sensor resolution when planning photogrammetric flights [58], we encourage additional enhancements to point-matching algorithms and other elements of the structure-from-motion workflow designed specifically to deal with complex forest scenes. We believe that there is more information in stereo photographs than what is currently being delivered by contemporary software such as Pix4D.

Most of the factors that currently limit DAP datasets have little impact on the data-collection process of LiDAR. As a result, our LiDAR data was able to detect very small openings, even though its point density was much lower $\left(\sim 40 \mathrm{pts} / \mathrm{m}^{2}\right)$ than that of our DAP data $\left(>200 \mathrm{pts} / \mathrm{m}^{2}\right)$. As mentioned, this observation confirms the findings of White et al. [8], who compared lower-density LiDAR (11.6 points $\left./ \mathrm{m}^{2}\right)$ and DAP $\left(12.27 \mathrm{~m}^{2}\right)$ in the temperate rain forest of British Columbia. They found significant differences in opening sizes and numbers, as well as large differences in the overall accuracies of the detection methods. These large errors further commensurate the results produced by Zielewska-Büttner et al. [65], who used fixed-height thresholds on DAP data to detect canopy openings in southern Germany. They found errors of omission to be $48 \%$ in tall-growth forests.

Our results showed that there was little value in integrating LiDAR and DAP for the purpose of mapping canopy openings in our study area. This is because the same DSM is used for both the DAP and hybrid techniques, which is the most important factor to binary opening/no-opening detection. The real value of the hybrid dataset comes in estimating canopy height, which is improved substantially by the canopy-penetrating abilities of LiDAR.

It must be noted that our recommendations regarding the use of DAP and hybrid datasets is directed at mapping structural-opening features only. For other applications (e.g., canopy height mapping [36,40], plot metrics [3,36], and microtopography characterization [66]), photogrammetric techniques may produce much better results. However, evaluating those attributes was beyond the scope of this study.

\section{Conclusions}

Our investigation reveals DAP-derived products, either with or without the enhancement of a LiDAR-based DTM, to be poor alternatives to LiDAR for mapping the full range of canopy openings in the boreal forest. While large openings are well-mapped with photogrammetric data, we found these products to be hindered by occlusions, mis-matched tie points, and other optical challenges, making small openings difficult to detect and delineate. While we did not quantify it specifically, we suspect that there is more information in the underlying stereo photography than what is currently being derived by contemporary structure-from-motion software such as Pix4D.

Given that DAP is an attractive, affordable, and easily accessible data source, further research into the derivation of detailed CHMs from either DAP or hybrid data sets is recommended, and we look forward to future methodological enhancements designed to address the specific challenges posed 
by structure-from-motion in complex forest scenes. At this moment, DAP's and the hybrid model's strength is clearly the affordable detection and delineation of larger-sized $\left(>200 \mathrm{~m}^{2}\right)$ forest openings. Expanding the capabilities of DAP would facilitate additional monitoring, modeling, and ultimately management applications in the boreal forest. However, currently, our observation is that DAP cannot produce the accuracies needed for the complete characterization of complex canopy structures, which include very small $\left(<10 \mathrm{~m}^{2}\right)$ openings. However, the results produced in this and other studies justify optimism that with further development, enhanced 3D modeling of forest structure with DAP is forthcoming.

Supplementary Materials: The following are available online at http://www.mdpi.com/2072-4292/11/16/1919/s1.

Author Contributions: A.D. processed the data and analyzed the results, wrote the paper, and is the main author of the article. M.M.R. pre-processed the data, helped with the technical challenges, aggregated results and helped editing and writing the paper. G.J.M. supported the process by contributing substantial, methodological and technical ideas, and helped with writing and reviewing the paper. J.L. helped in planning fieldwork, contributed substantial and methodological ideas and assisted in reviewing the paper. R.L. helped in scoping the study and also assisted in reviewing the manuscript.

Funding: This research was funded by a Natural Sciences and Engineering Research Council of Canada Collaborative Research and Development Grant (CRDPJ 469943-14) in conjunction with Alberta-Pacific Forest Industries, Cenovus Energy, ConocoPhillips Canada, Devon Canada Corporation, and the Regional Industry Caribou Collaboration.

Acknowledgments: We gratefully acknowledge the valuable contributions provided by Drs. David Goldblum and Guillermo Castilla during project conceptualization and data analysis. Keifer Biddle, Alex Hamilton, Gus Lopes-Queiroz and Jack Sugden assisted with field work. The presentation of our results was greatly improved by the comments of four anonymous reviewers. Many thanks to Ralf Ludwig for establishing the connection between the researchers within the context of the Alberta-Bavaria Research Network (ABBY-Net) and supervising the process remotely.

Conflicts of Interest: The authors declare no conflicts of interest. The funders had no role in the design of the study; in the collection, analyses, or interpretation of data; in the writing of the manuscript, or in the decision to publish the results.

\section{References}

1. Burton, P.J.; Parisien, M.A.; Hicke, J.A.; Hall, R.J.; Freeburn, J.T. Large fires as agents of ecological diversity in the North American boreal forest. Int. J. Wildl. Fire 2008, 17, 754-767. [CrossRef]

2. Senf, C.; Pflugmacher, D.; Hostert, P.; Seidl, R. Using Landsat time series for characterizing forest disturbance dynamics in the coupled human and natural systems of Central Europe. ISPRS J. Photogramm. Remote Sens. 2017, 130, 453-463. [CrossRef] [PubMed]

3. Dabros, A.; Pyper, M.; Castilla, G. Seismic lines in the boreal and arctic ecosystems of North America: Environmental impacts, challenges, and opportunities. Environ. Rev. 2018, 16, 1-16. [CrossRef]

4. Lee, P.; Boutin, S. Persistence and developmental transition of wide seismic lines in the western Boreal Plains of Canada. J. Environ. Manag. 2006, 78, 240-250. [CrossRef] [PubMed]

5. Schroeder, T.A.; Wulder, M.A.; Healey, S.P.; Moisen, G.G. Mapping wild fire and clearcut harvest disturbances in boreal forests with Landsat time series data. Remote Sens. Environ. 2011, 115, 1421-1433. [CrossRef]

6. Rahman, M.M.; McDermid, G.J.; Strack, M.; Lovitt, J. A new method to map groundwater table in peatlands using unmanned aerial vehicles. Remote Sens. 2017, 9, 1057. [CrossRef]

7. Lertzman, K.P.; Sutherland, G.D.; Inselberg, A.; Saunders, S.C. Canopy Gaps and the Landscape Mosaic in a Coastal Temperate Rain Forest. Ecology 1996, 77, 1254-1270. [CrossRef]

8. White, J.C.; Tompalski, P.; Coops, N.C.; Wulder, M.A. Comparison of airborne laser scanning and digital stereo imagery for characterizing forest canopy gaps in coastal temperate rainforests. Remote Sens. Environ. 2018, 208, 1-14. [CrossRef]

9. Dabros, A.; Hammond, H.E.J.; Pinzon, J.; Pinno, B.; Langor, D. Edge influence of low-impact seismic lines for oil exploration on upland forest vegetation in northern Alberta (Canada). For. Ecol. Manag. 2017, 400, 278-288. [CrossRef]

10. Canham, C.D.; Denslow, J.S.; Platt, W.J.; Runkle, J.R.; Spies, T.A.; White, P.S. Light regimes beneath closed canopies and tree-fall gaps in temperate and tropical forests. Can. J. For. Res. 1990, 20, 620-631. [CrossRef] 
11. Feldmann, E.; Drößler, L.; Hauck, M.; Kucbel, S.; Pichler, V.; Leuschner, C. Forest Ecology and Management Canopy gap dynamics and tree understory release in a virgin beech forest, Slovakian Carpathians. For. Ecol. Manag. 2018, 415-416, 38-46. [CrossRef]

12. Lawton, R.; Putz, F.E. Natural Disturbance and Gap-Phase Regeneration in a Wind-Exposed Tropical Cloud Forest. Ecology 1988, 69, 764-777. [CrossRef]

13. Runkle, J.R. Guidelines and Sample Protocol for Sampling Forest Gaps; US Department of Agriculture, Forest Service, Pacific Northwest Research Station: Portland, OR, USA, 1992; Volume 283, ISBN 0894192090303.

14. Hebblewhite, M. Billion dollar boreal woodland caribou and the biodiversity impacts of the global oil and gas industry. Biol. Conserv. 2017, 206, 102-111. [CrossRef]

15. Lovitt, J.; Rahman, M.M.; Saraswati, S.; McDermid, G.J.; Strack, M.; Xu, B. UAV remote sensing can reveal the effects of low-impact seismic lines on surface morphology, hydrology, and methane $(\mathrm{CH} 4)$ release in a boreal treed bog. J. Geophys. Res. Biogeosci. 2018. [CrossRef]

16. Brokaw, N.V.L. The Definition of Treefall Gap and Its Effect on Measures of Forest Dynamics. Biotropica 1982, 14, 158-160. [CrossRef]

17. Pickett, S.T.A.; Wu, J.; Cadenasso, M.L. Patch dynamics and the ecology of disturbed ground: A framework for synthesis. In Ecosystems of Disturbed Ground. Ecosystems of the World; Walker, L.R., Ed.; Elsevier: Amsterdam, The Netherlands, 1999; Volume 16, pp. 707-722.

18. Baret, F.; Clevers, J.G.P.W.; Steven, M.D. The robustness of canopy gap fraction estimates from red and near-infrared reflectances: A comparison of approaches. Remote Sens. Environ. 1995, 54, 141-151. [CrossRef]

19. Liu, J.; Skidmore, A.K.; Jones, S.; Wang, T.J.; Heurich, M.; Zhu, X.; Shi, Y.F. Large off-nadir scan angle of airborne LiDAR can severely affect the estimates of forest structure metrics. ISPRS J. Photogramm. Remote Sens. 2018, 136, 13-25. [CrossRef]

20. Cescatti, A. Indirect estimates of canopy gap fraction based on the linear conversion of hemispherical photographs. Agric. For. Meteorol. 2006, 143, 1-12. [CrossRef]

21. Cohen, W.B.; Spies, T.A.; Fiorella, M. Estimating the age and structure of forests in a multi-ownership landscape of western Oregon, U.S.A. Int. J. Remote Sens. 1995, 16, 721-746. [CrossRef]

22. Rautiainen, M.; Stenberg, P.; Nilson, T. Estimating Canopy Cover in Scots Pine Stands. Silva Fenn. 2005, 39, 137-142. [CrossRef]

23. Rehush, N.; Waser, L.T. Assessing the structure of primeval and managed beech forests in the Ukrainian Carpathians using remote sensing. Can. J. For. Res. 2017, 47, 63-72. [CrossRef]

24. Hobi, M.L.H.; Ginzler, C.G.; Commarmot, B.C.; Bugmann, H. Gap pattern of the largest primeval beech forest of Europe revealed by remote sensing. ESA Ecosph. 2015, 6, 1-15. [CrossRef]

25. Nyamgeroh, B.B.; Groen, T.A.; Weir, M.J.C.; Dimov, P.; Zlatanov, T. Detection of forest canopy gaps from very high resolution aerial images. Ecol. Indic. 2018, 95, 629-636. [CrossRef]

26. Vepakomma, U.; St-Onge, B.; Kneeshaw, D. Spatially explicit characterization of boreal forest gap dynamics using multi-temporal lidar data. Remote Sens. Environ. 2008, 112, 2326-2340. [CrossRef]

27. Gaulton, R.; Malthus, T.J. LiDAR mapping of canopy gaps in continuous cover forests: A comparison of canopy height model and point cloud based techniques. Int. J. Remote Sens. 2010, 31, 1193-1211. [CrossRef]

28. Vehmas, M.; Packalén, P.; Maltamo, M.; Eerikäinen, K. Using airborne laser scanning data for detecting canopy gaps and their understory type in mature boreal forest. Ann. For. Sci. 2011, 68, 825-833. [CrossRef]

29. Bonnet, S.; Gaulton, R.; Lehaire, F.; Lejeune, P. Canopy gap mapping from airborne laser scanning: An assessment of the positional and geometrical accuracy. Remote Sens. 2015, 7, 11267-11294. [CrossRef]

30. Asner, G.P.; Kellner, J.R.; Kennedy-Bowdoin, T.; Knapp, D.E.; Anderson, C.; Martin, R.E. Forest Canopy Gap Distributions in the Southern Peruvian Amazon. PLoS ONE 2013, 8, e60875. [CrossRef] [PubMed]

31. Koukoulas, S.; Blackburn, G.A. Quantifying the spatial properties of forest canopy gaps using LiDAR imagery and GIS. Int. J. Remote Sens. 2004, 25, 3049-3071. [CrossRef]

32. Koukoulas, S.; Blackburn, G.A. Spatial relationships between tree species and gap characteristics in broad-leaved deciduous woodland. J. Veg. Sci. 2005, 16, 587-596. [CrossRef]

33. Lefsky, M.A.; Cohen, W.B.; Parker, G.G.; Harding, D.J. Lidar Remote Sensing for Ecosystem Studies. Bioscience 2002, 52, 19-30. [CrossRef]

34. Næsset, E. Vertical height errors in digital terrain models derived from airborne laser scanner data in a boreal-alpine ecotone in Norway. Remote Sens. 2015, 7, 4702-4725. [CrossRef] 
35. Leberl, F.; Irschara, A.; Pock, T.; Meixner, P.; Gruber, M.; Scholz, S.; Wiechert, A. Point Clouds: Lidar versus 3D Vision. Photogramm. Eng. Remote Sens. 2010, 76, 1123-1134. [CrossRef]

36. St-Onge, B.; Vega, C.; Fournier, R.A.; Hu, Y. Mapping canopy height using a combination of digital stereo-photogrammetry and lidar. Int. J. Remote Sens. 2008, 29, 3343-3364. [CrossRef]

37. Filipelli, S.K.; Lefsky, M.A.; Rocca, M.E. Comparison and integration of lidar and photogrammetric point clouds for mapping pre-fire forest structure. Remote Sens. Environ. 2019, 224, 152-166. [CrossRef]

38. Holopainen, M.; Vastaranta, M.; Karjalainen, M.; Karila, K.; Kaasalainen, S.; Honkavaara, E.; Hyyppä, J. Forest Inventory Attribute Estimation Using Airborne Laser Scanning, Aerial Stereo Imagery, Radargrammetry and Interferometry-Finnish Experiences of the 3D Techniques. ISPRS Ann. Photogramm. Remote Sens. Spat. Inf. Sci. 2015, II-3/W4, 63-69. [CrossRef]

39. White, J.C.; Wulder, M.A.; Vastaranta, M.; Coops, N.C.; Pitt, D.; Woods, M. The utility of image-based point clouds for forest inventory: A comparison with airborne laser scanning. Forests 2013, 4, 518-536. [CrossRef]

40. Remondino, F.; Spera, M.G.; Nocerino, E.; Menna, F.; Nex, F. State of the art in high density image matching. Photogramm. Rec. 2014, 29, 144-166. [CrossRef]

41. Zhang, K. Identification of gaps in mangrove forests with airborne LIDAR. Remote Sens. Environ. 2008, 112, 2309-2325. [CrossRef]

42. Wallace, L.; Lucieer, A.; Malenovsky, Z.; Turner, D. Assessment of Forest Structure Using Two UAV Techniques: A Comparison of Airborne Laser Scanning and Structure from Motion (SfM) Point Clouds. Forests 2016, 7, 62. [CrossRef]

43. Swinfield, T.; Lindsell, J.A.; Williams, J.V.; Harrison, R.D.; Agustiono, H.; Gemita, E.; Schonlieb, C.B.; Coomes, D.A. Accurate Measurement of Tropical Forest Canopy Heights and Aboveground Carbon Using Structure From Motion. Remote Sens. 2019, 11, 928. [CrossRef]

44. Vastaranta, M.; Yrttimaa, T.; Saarinen, N.; Yu, X.W.; Karjalainen, M.; Nurminen, K.; Karila, K.; Kankare, V.; Luoma, V.; Pyorala, J.; et al. Airborne Laser Scanning Outperforms the Alternative 3D Techniques in Capturing Variation in Tree Height and Forest Density in Southern Boreal Forests. Balt. For. 2018, 24, $268-277$.

45. Cao, L.; Liu, H.; Fu, X.Y.; Zhang, Z.N.; Shen, X.; Ruan, H.H. Comparison of UAV LiDAR and Digital Aerial Photogrammetry Point Clouds for Estimating Forest Structural Attributes in Subtropical Planted Forests. Forests 2019, 10, 145. [CrossRef]

46. Graham, A.; Coops, N.C.; Wilcox, M.; Plowright, A. Evaluation of Ground Surface Models Derived from Unmanned Aerial Systems with Digital Aerial Photogrammetry in a Disturbed Conifer Forest. Remote Sens. 2019, 11, 84. [CrossRef]

47. Iqbal, I.A.; Osborn, J.; Lucieer, A. A comparison of area-based forest attributes derived from airborne laser scanner, small-format and medium-format digital aerial photography. Int. J. Appl. Earth Obs. Geoinf. 2019, 76, 231-241. [CrossRef]

48. Swetnam, T.L.; Gillan, J.K.; Sankey, T.T.; Mcclaran, M.P.; Nichols, M.H.; Heilman, P.; Mcvay, J. Considerations for Achieving Cross-Platform Point Cloud Data Fusion across Different Dryland Ecosystem Structural States. Front. Plant Sci. 2018, 8, 1-13. [CrossRef] [PubMed]

49. Pearse, G.D.; Dash, J.P.; Persson, H.J.; Watt, M.S. Comparison of high-density LiDAR and satellite photogrammetry for forest inventory. ISPRS J. Photogramm. Remote Sens. 2018, 142, 257-267. [CrossRef]

50. Fankhauser, K.E.; Strigul, N.S.; Gatziolis, D. Augmentation of Traditional Forest Inventory and Airborne Laser Scanning with Unmanned Aerial Systems and Photogrammetry for Forest Monitoring. Remote Sens. 2018, 10, 1562. [CrossRef]

51. St-Onge, B.; Audet, F.-A.; Bégin, J. Characterizing the Height Structure and Composition of a Boreal Forest Using an Individual Tree Crown Approach Applied to Photogrammetric Point Clouds. Forests 2015, 6, 3899-3922. [CrossRef]

52. White, J.C.; Stepper, C.; Tompalski, P.; Coops, N.C.; Wulder, M.A. Comparing ALS and image-based point cloud metrics and modelled forest inventory attributes in a complex coastal forest environment. Forests 2015, 6, 3704-3732. [CrossRef]

53. Ni, W.; Jon, K.; Zhang, Z.; Sun, G. Features of point clouds synthesized from multi-view ALOS/PRISM data and comparisons with LiDAR data in forested areas. Remote Sens. Environ. 2014, 149, 47-57. [CrossRef]

54. Rahlf, J.; Breidenbach, J.; Solberg, S.; Naesset, E.; Astrup, R. Comparison of four types of 3D data for timber volume estimation. Remote Sens. Environ. 2014, 155, 325-333. [CrossRef] 
55. Vastaranta, M.; Wulder, M.A.; White, J.C.; Pekkarinen, A.; Tuominen, S.; Ginzler, C.; Kankare, V.; Holopainen, M.; Hyyppä, J.; Hyyppä, H. Airborne laser scanning and digital stereo imagery measures of forest structure: Comparative results and implications to forest mapping and inventory update. Can. J. Remote Sens. 2013, 39, 382-395. [CrossRef]

56. Gil, A.L.; Núñez-Casillas, L.; Isenburg, M.; Benito, A.A.; Bello, J.J.R.; Arbelo, M. A comparison between LiDAR and photogrammetry digital terrain models in a forest area on Tenerife Island. Can. J. Remote Sens. 2013, 39, 396-409.

57. Bohlin, J.; Wallerman, J.; Fransson, J.E.S. Forest variable estimation using photogrammetric matching of digital aerial images in combination with a high-resolution DEM. Scand. J. For. Res. 2012, 27, 692-699. [CrossRef]

58. Järnstedt, J.; Pekkarinen, A.; Tuominen, S.; Ginzler, C.; Holopainen, M.; Viitala, R. Forest variable estimation using a high-resolution digital surface model. ISPRS J. Photogramm. Remote Sens. 2012, 74, 78-84. [CrossRef]

59. Mccarthy, J. Gap dynamics of forest trees: A review with particular attention to boreal forests. Environ. Rev. 2001, 9, 1-59. [CrossRef]

60. Kottek, M.; Grieser, J.; Beck, C.; Rudolf, B.; Rubel, F. World map of the Köppen-Geiger climate classification updated. Meteorol. Z. 2006, 15, 259-263. [CrossRef]

61. Downing, D.J.; Pettapiece, W.W. Natural Regions and Subregions of Alberta; Government of Alberta: Edmonton, AB, Canada, 2006; ISBN 0778545725.

62. Westoby, M.J.; Brasington, J.; Glasser, N.F.; Hambrey, M.J.; Reynolds, J.M. "Structure -from- Motion" photogrammetry: A low -cost, effective tool for geoscience applications Introduction. Geomorphology 2012, 179, 300-314. [CrossRef]

63. Kershaw, J.A.; Ducey, J.M.J.; Beers, T.W.; Husch, B. Forest Mensuration, 5th ed.; John Wiley \& Sons: Chichester, UK; Hoboken, NJ, USA, 2016.

64. Chen, S.; McDermid, G.J.; Castilla, G.; Linke, J. Measuring vegetation height in linear disturbances in the boreal forest with UAV photogrammetry. Remote Sens. 2017, 9, 1257. [CrossRef]

65. Zielewska-Büttner, K.; Adler, P.; Ehmann, M.; Braunisch, V. Automated detection of forest gaps in spruce dominated stands using canopy height models derived from stereo aerial Imagery. Remote Sens. 2016, 8, 175. [CrossRef]

66. Lovitt, J.; Rahman, M.M.; McDermid, G.J. Assessing the value of UAV photogrammetry for characterizing terrain in complex peatlands. Remote Sens. 2017, 9, 1-13. 